\title{
Nuevo registro de Nymphaea prolifera (Nymphaeaceae) para México
}

Recientemente durante la revisión de la familia Nymphaeaceae para el estado de Veracruz, se encontró en el material herborizado un ejemplar no identificado de Nymphaea, que al estudiarlo resultó ser el único registro que se tiene para México de N. prolifera.

Especie del subgénero Hydrocallis de distribución tropical, ha sido reportada del norte de Argentina, sur de Brasil, oeste de Ecuador, Paraguay, Costa Rica y El Salvador (Wiersema,1987); con este nuevo registro se amplia su área de distribución septentrional en el Continente Americano.

Esta especie, como el resto del subgénero Hydrocallis presenta antesis nocturna y se caracteriza por la presencia de flores tuberíferas que se producen por abortamiento de las flores, desarrollando un tubérculo y verticilos de hojas y flores tuberíferas adicionales. Wiersema (1987) señala que este fenómeno en Nymphaea es común observarlo sólo en esta especie y en $N$. lasiophylla. La principal característica distintiva entre ambas especies es la forma de los apéndices carpelares, que son clavados en $N$. prolifera y ahusado-lingulados en N. lasiophylla (Wiersema, 1987).

Nymphaea prolifera se recolectó en potreros temporalmente inundados a la orilla de la carretera, a profundidades de 30 a $60 \mathrm{~cm}$. Las observaciones de campo indican que las poblaciones aparecen poco después de la llegada de las lluvias, la floración se observó durante el mes de septiembre. Las flores son muy escasas, antes de la antesis flotan a nivel del agua y se desprenden con facilidad; en cambio, las flores tuberíferas son muy abundantes, se encuentran sumergidas pero también se desprenden rápidamente, por lo que es común observar numerosos tubérculos flotando ligeramente debajo del nivel del agua. Estos tubérculos probablemente quedan enterrados en el fango cuando baja el nivel del agua.

Con este nuevo registro aumenta a cinco el número de especies del subgénero Hydrocallis registradas para México por Ramírez-García y Novelo (1989).

MATERIAL DE REFERENCIA: VERACRUZ, zanjas inundadas a los lados de la carretera a $37 \mathrm{~km}$ de Veracruz, sobre la carretera a Alvarado, 25 VIII 1977, Lot 2480 (MEXU), 22 IX 1990, Olvera 67, 68 (MEXU); mun.: Veracruz, zona inundada a la orilla

Olvera M, Lot A. 1991. Nuevo registro de Nymphaea prolifera (Nymphaeaceae) para México. Boletín de la Sociedad Botánica de México 51: 93-94. 
de la carretera cerca del aeropuerto, a $11 \mathrm{~km}$ del Puerto de Veracruz, 22 IX 1990, Olvera 64, 66 (MEXU).

\section{LITERATURA CITADA}

RAMÍREZ-GARCÍA, P. y A. NOVELO. 1989. Nymphaea amazonum (Nymphaeaceae) en México; clave de las especies del subgénero Hydrocallis en el país. An. Inst. Biol. Univ. Nac. Autón. México Ser. Bot. (Núm. único) 58:87-92.

WIERSEMA, J.H. 1987. A monograph of Nymphaea subgenus Hydrocallis (Nymphaeaceae). Syst. Bot. Monogr. 16:1-112.

MARTIIA OlVERA y ANTONIO Lot. Departamento de Botánica, Instituto de Biología, Universidad Nacional Autónoma de México, Apdo. Postal 70-233, Delegación Coyoacán, 04510, México, D.F. 